\title{
An Editorial Note
}

With this issue ACM inaugurates a new periodical, Computing Surveys, the survey and tutorial journal of the ACM. In this age of increasing specialization, it becomes more and more difficult for the computing professional, experienced or novice, to be expert in all areas of the computing field. The purpose of Computing Surveys is to help fill in the gaps-to make the specialist aware of the state-of-the-art in the diversified areas of this rapidly expanding field.

Accordingly, articles in Computing Surveys assume that the reader has had little prior contact with the subject matter and only limited exposure to prerequisite subjects. Papers requiring of the reader more specialized background will continue to appear in the companion periodicals, Communications of the ACM and Journal of the Association for Computing Machinery. Concomitantly, however, the new publication is intended for the professional, easily challenged and less easily defeated by exposure to articles outside his purview; consequently, it will maintain the high professional standards expected of our publications.

It is our objective to publish articles with broadly based appeal, responsive to the needs of a wide spectrum of the computing community. Obviously, we do not guarantee that each paper published will enjoy universal interest; hopefully, most readers will find some papers in each issue informative and understandable.

A new publication requires a lengthy gestation period, as well as the involvement of numerous people. Delivery, however, is best entrusted to a single individual, and I am grateful to Dr. William S. Dorn for undertaking this difficult task for Computing Surveys. As it is the reader who has the most vital interest in shaping a new publication, I urge you to submit opinions, suggestions, and (hopefully) papers to the Editor-inChief.

Aaron Finerman

Chairman, ACM Editorial Board 